\title{
Analysis of U.S. Consumption-related Industry Based on Fama-French Model Under COVID-19
}

\author{
Yang $\mathrm{Cao}^{1, \dagger}$, Baozhen Ouyang ${ }^{2, \dagger}$, Mingji Xi ${ }^{3, *},{ }^{*}$, Runze $\mathrm{Yu}^{4, \dagger}$ \\ ${ }^{1}$ South Kensington Campus, Imperial College London, London SW7 2AZ, Great Britain \\ ${ }^{2}$ Faculty of Social Sciences, The University of Sheffield, Sheffield S10 2TN, Great Britain \\ ${ }^{3}$ Business School, The Chinese University of Hong Kong, Hong Kong 999077, China \\ ${ }^{4}$ School of Finance, Zhejiang Gongshang University, Hangzhou 310018, China \\ *Corresponding author. Email: Email:1906070424@pop.zjgsu.edu.cn \\ These authors contributed equally.
}

\begin{abstract}
Many researchers have contributed much to asset pricing theory and continuously try to find the best model to capture stock average return. The CAPM model and Fama-French 3-factor model, Fama-French 5-factor model is another way to capture the return rates and their changes. At the beginning of 2020, COVID-19 spread all over the world, which influenced the U.S. stock market a lot. Therefore, this paper tends to test the performances of Fama-French 5 factors models on consumption-related industry in U.S stock market before and after the outbreak of COVID-19 with multiple linear regression and examine the reasons. The results show that Fama-French 5-factor model captures the return of stocks in the U.S. stock market. As for specific factors, Market risk (MKT) shows significance both before and after COVID-19, and the power of explanation becomes stronger, that means this factor affects the return of stocks in the U.S. stock market a lot. Small minus big (SMB) varies a lot during the pandemic, it becomes insignificant after the epidemic and its negative coefficient indicates the excess return was due to a large size company. Due to COVID-19, High minus Low (HML) began to play a positive role in soda and smoke market. For five-factor model, Robust Minus Weak (RMW) changed its position and became weaker. The position of Conservative Minus Aggressive (CMA) remained unchanged. After the outbreak, CMA became less significant.
\end{abstract}

Keywords: Fama-French Model, Covid-19, Consumption-related industry, U.S. stock market

\section{INTRODUCTION}

\subsection{Background}

The novel coronavirus pneumonia epidemic excerts a substantial impact on the U.S. Economy, with the CPI rising $2.3 \%$ year-over-year in February 2020 and at a higher level of $3 \%$ compared to January. Among which food prices rose $1.7 \%$, boosted by logistical stagnation, $0.3 \%$ compared to January. According to Intrafish, total business in the U.S. food service industry fell $36 \%$. Although the U.S. Commerce Department's Bureau of Economic Analysis released data showing that U.S. economic output in the second quarter has returned to pre-epidemic levels, the spread of the Delta strain of new coronavirus also brought new uncertainty to the U.S. economic recovery. In the second quarter of 2021, the U.S. economy grew at a discounted annual rate of $6.5 \%$, the fourth consecutive quarter of growth, but inferior to the average market expectations of $8.5 \%$ growth.

The fundamental component of the Capital Asset Pricing Model (CAPM) is the study of the quantitative relationship between the expected rate of return on assets in the securities market and the risky assets, i.e., what rate of return an investor should receive in order to compensate for a particular degree of risk, and how the equilibrium price is formed. The significance of the capital asset pricing model in practice is its application to asset valuation, capital cost budgeting, and resource allocation. The model concentrates on the sensitivity of security returns to changes in market portfolio returns, assisting investors in determining whether the additional return received is commensurate with the risk involved. 


\subsection{Related Research}

Cao et al. Represent a comparison between Fama and French's model and artificial neutral networks in predicting the Chinese stock market. Cao et al. tell us that stock returns in emerging markets are influenced by many different factors, which significantly affects the stock returns in developed markets. Besides, neutral network is a very useful tool to depict the change of stock prices in emerging markets. In general, neutral networks can enhance investors' ability to predict stock prices [1]. Gaunt examines size and book to market effects and the Fama French three-factor asset pricing model. Gaunt compared Fama French three-factor model with CAPM with the data of Australian stock market. Compared with CAPM, Fama French threefactor model tends to be more explanatory. CAPM is not good at explaining realized returns. In conclusion, Fama French three-factor model better depicts the stock price change in Australia. At the same time, Australia will play an increasingly important role in examining the external validity of conclusions reached by asset pricing research performed using influential US data [2]. KUBOTA and TAKEHARA examined whether the Fama and French five-factor Model work well in Japan. The research is based on Japan's data between 19782014. Fama French five-factor model is often used to estimate the returns of American stocks. In conclusion, both the RMW betas and the CMA betas are weakly associated with the cross-sectional variations of stock returns, which is significantly different from the US evidence. Fama and French five-factor model, which fits US data, cannot be an adequate benchmark pricing model for Japanese data during our sampling period from the year 1978 to the year 2014 [3]. Chiah et al. examine the role of the Fama-French five-factor model in Australian stock pricing by using a substantial sample from 1982 to 2013. The study adds comparative evidence from international stock markets to the model's rigorous out-of-sample test. The findings demonstrate that pricing profitability and investment can increase the three-factor model's explanatory power. The five-factor model is able to explain more asset pricing anomalies than other competing asset pricing models, including the three-factor model and the Carhart four-factor model [4].

Sun examines how the Fama-French five-factor model performed in the US market before and after the Covid-19 epidemic. The OLS method is used to analyze 49 Fama-French industry portfolios, and the results show that after the epidemic, the efficiency of the FamaFrench five-factor model improved in all industries, but unexplained factor behavior rose. The pandemic has a large influence on Fama-French factor beta in most industries and has a considerable impacts on portfolio performance and factor exposures [5]. Bannigidadmath et al. examine the impact of particular government policies on stock markets in 25 countries. Using an event study approach to examine four specific policies, namely country lockdown, the stimulus package, the travel ban, and monetary policy, the study finds that overall government policies, while aimed at mitigating the effects of COVID-19, had more negative than positive effects [6]. Fernandes explained why comparisons with previous incidents, such as SARS, are impossible. Then Fernandes highlighted the most recent news as well as credible data that can be used to make forecast, which concludes that the impact will be quite asymmetric across different industries. Besides, countries with more service-oriented economies will be more affected. Fernandes then went over some conceivable scenarios and their implications for the economy. According to the findings, Fernandes pointed out that each additional month of crisis costs $2.5-3 \%$ of global GDP on average. In addition, the economic burdens of a recession are dispersed unequally. Also, GDP growth would be slowed from 3\% to $6 \%$ depending on different countries [7]. Mckibbin and Fernando built their work on Lee and Mckibbin's previous research into the economics of SARS and Pandemic Influenza. Besides, Mckibbin and Fernando also reviewed the existing evidence on desease macroeconomic costs and emphasized its strengths in assessing illness macroeconomics by adopting the global macroeconomic model (G-Cubed). The findings of the seven situations that were simulated using the model are discussed by using this model. Mckibbin and Fernando emphasize, if COVID-19 becomes a pandemic, the costs will rise significantly and cause huge economic losses. Governments are therefore required to adopt appropriate financial and health policies, such as calls for good health practices, and make adequate investment in health care systems [8].

Chen et al. used high-frequency indicators to examine the economic impact of COVID-19 in Europe and the United States during the early stages of the epidemic and give an assessment of the economic effects of the pandemic and non-pharmaceutical solutions. Chen also show the extent to which nonpharmaceutical interventions (NPIs) affect mobility and economic activity by comparing the timing of their changes with the date when the policies are introduced. It was suggested that there is a strong link between mitigation policies and the number of cases and economic activity, therefore, governments may have to choose between curbing the pandemic and maintaining economic activity. Besides, what makes a region vulnerable to major epidemics may be linked to what makes the economic impact significant, such as the prevalence of non-essential service jobs. Moreover, it was argued that the economy will not recover immediately after the government canceled the NPIs, but will recover slowly as people feel more comfortable resuming normal activities [9]. Petcova focused on how Fama-French factor is proper for making new changes 
in predictive variables. He first illustrates Fama-French model is effective in intertemporal asset pricing model. Then he considered Fama-French model with innovations in state variables and found that FamaFrench model is consistent, thanks to CAPM. Also, Fama-French Factors are Proxy for Innovations by showing a model of excess market and some innovations. However, it is important to specify the identity of the state variables to conclude whether they are proxy for innovations [10]. Philip, Howard, and Robert show that Fama-French could explain crosssectional variation in equity returns occurs as SMB and HML both are proxying for default risk. Ferguson and Shockley (2003) also obtained a model with market factors, a default factor, and a leverage factor. They found that Fama-French model cannot explain returns on portfolios formed by sorts on past returns. Also, Philip, Howard, and Robert got an idea that they can also build a model to strengthen their assumptions [11]. In addition, Alan et al. illustrate the principle of FamaFrench model, which expands on the capital asset pricing model (CAPM) by adding size risk and value risk factors to the market risk factor in CAPM. Also, they used sequential sorts on size, BTM, and momentum to test these alternative factor models. But Lo and MacKinlay (1990) and Lewellen et al. (2010) did not agree with that idea because portfolios' characteristics have been used to form the factors in the first place [12].

\subsection{Objective}

Fama-French five-factor model was adopted to analyze consumption-related industries. The excess return can be explained by market risk, market value risk, book market value ratio risk, profitability level risk, and investment level risk. Compared with Fama-French three-factor model, the five-factor model better explains stocks' excess return. The way to estimate coefficients is multiple linear regression. Investors can judge each variable's conspicuousness with t-test. If $t$ is more than the critical value, we refuse the null hypothesis, that means the variable is conspicuousness. According to the consequence, we will understand how to change the orientation of the investment.

\section{METHOD}

\subsection{The Capital Asset Pricing Model}

The Capital Asset Pricing Model (CAPM) is a mathematical model that outlines the link between a security's expected return and the risk associated with investing in a security. It demonstrates that a security's anticipated return is equal to the return without risk plus a risk premium based on the security's beta.

$$
\mathrm{R}_{\mathrm{i}}-\mathrm{R}_{\mathrm{f}}=\beta\left(\mathrm{R}_{\mathrm{M}}-\mathrm{R}_{\mathrm{f}}\right)
$$

Where $\mathrm{R}_{\mathrm{i}}$ (expected return on security) represents the expected yield of a capital asset over time. $R_{f}$ (risk free rate), is usually equal to the yield on a 10-year government bond. Beta (beta of security) is a measure of its volatility of returns by assessing the variation of a stock's price fluctuations relative to the general market. A beta greater than one indicates that the security will rise more, and vice versa. $\mathrm{Rm}-\mathrm{R}_{\mathrm{f}}$ (risk premium) is the additional return necessary to pay investors for investing in a riskier asset class over and above the risk-free rate. The higher the market risk premium, the more volatile the market or asset class is.

\subsection{Fama-French five-factor model theory}

According to Fama and French, the Fama French five-factor model is based on the Fama French threefactor model [13]. It is constructed by 6 value-weight portfolios and based on the dividend discount concept, which asserts that the current value of equities is determined by future dividend payments. To better capture the relationship between risk and return.

$$
\begin{aligned}
& \mathbf{R}_{\mathrm{i}}-\mathbf{R}_{\mathbf{f}}=\beta_{1}\left(\mathrm{R}_{\mathrm{M}}-\mathbf{R}_{\mathrm{f}}\right)+\beta_{2} \mathrm{SMB}+\beta_{3} \mathrm{HML}+\beta_{4} \mathrm{RMW}+\beta \\
& { }_{5} \mathrm{CMA}(2)
\end{aligned}
$$

SMB (Small Minus Big) represents the expected excess return rate of small-cap companies relative to large-cap companies.

$\operatorname{SMB}(B / M)=\frac{1}{3}($ Small Value + Small Neutral + Small Growth)-1/3(Big Value) +Big Neutral+Big Growth (3)

$\mathrm{SMB}(\mathrm{OP})=\frac{1}{3}($ Small Robust + Small Neutral + Small

Weak)-1/3(Big Robust+Big Neutral+Big Weak)

$\mathrm{SMB}(\mathrm{INV})=\frac{1}{3}($ Small Conservative + Small Neutral+Small Aggressive)-1/3(Big Conservative+Big Neutral+Big Aggressive)

$$
\mathrm{SMB}=\frac{1}{3}\left(\mathrm{SMB}_{(\mathrm{B} / \mathrm{M})}+\mathrm{SMB}_{(\mathrm{OP})}+\mathrm{SMB}_{(\mathrm{INV})}\right)
$$

HML (High Minus Low) is the difference between performance on diversified equity portfolios with high and low book-to-market ratios. It can be calculated by taking the average of the two value stocks and deducting the average of the growth stock

$$
\begin{gathered}
\mathrm{HML}=\frac{1}{2}(\text { Small Value }+ \text { Big Value })-\frac{1}{2}(\text { Small Growth }+ \text { Big } \\
\text { Growth })
\end{gathered}
$$

Robust Minus Weak (RMW) is the difference between the returns of different portfolios of stocks with high, stable, and low returns.

$$
\begin{gathered}
\mathrm{RMW}=\frac{1}{2} \text { (Small Robust+Big Robust) }-\frac{1}{2} \text { (Small } \\
\text { Weak+Big Weak })
\end{gathered}
$$

CMA (Conservative Minus Aggressive) refers to the yield gap between the average of two conservative 
investment portfolios deduct the average of two aggressive investment portfolios.

$$
\begin{aligned}
\mathrm{CMA} & =\frac{1}{2}(\text { Small Conservative }+ \text { Big Conservative })-\frac{1}{2} \\
& (\text { Small Aggressive }+ \text { Big Aggressive })
\end{aligned}
$$

\section{RESULTS}

According to the details of French's data library, four industries, including food, soda, beer, and smoke, are selected to evaluate the impact of COVID-19 on these industries. As mentioned above, these fields are necessities to society and have many cases to deduce to obtain a more accurate result. In addition, Covid-19 has influenced consumption-related industries a lot due to the government policies like lockdown and selfquarantine or the change in eating/entertaining habits due to the huge pandemic.

According to professor French's research, the value of Mkt-RF, SMB, HML, RMW, CMA, and RF are needed from May $1^{\text {st }}$ in 2020 to the end of 2020. By using the method of multiple linear regression can calculate t-Stat and $\mathrm{P}$-value at each time also with coefficient value.

\begin{tabular}{|c|c|c|c|c|c|c|c|c|c|}
\hline \multirow[t]{2}{*}{ PERIOD } & \multirow{2}{*}{$\begin{array}{c}\text { INDUSTRY } \\
\text { Factor }\end{array}$} & \multicolumn{2}{|c|}{ FOOD } & \multicolumn{2}{|c|}{ SODA } & \multicolumn{2}{|c|}{ BEER } & \multicolumn{2}{|c|}{ SMOKE } \\
\hline & & Coefficient & t Stat & Coefficient & t Stat & Coefficient & t Stat & Coefficient & t Stat \\
\hline \multirow[t]{5}{*}{ BEFORE } & Mkt-Rf & 0.623 & 13.955 & 0.871 & 8.34 & 0.771 & 6.529 & 0.584 & 4.582 \\
\hline & SMB & 0.187 & 2.226 & 0.417 & 2.121 & 0.082 & 0.371 & -0.045 & -0.188 \\
\hline & HML & -0.108 & -1.259 & -0.076 & -0.379 & 0.189 & 0.828 & -0.331 & -1.345 \\
\hline & RMW & -0.127 & -0.905 & 0.439 & 1.338 & -0.049 & -0.132 & 0.038 & 0.095 \\
\hline & CMA & 0.744 & 4.483 & 0.057 & 0.147 & -0.390 & -0.888 & 0.429 & 0.904 \\
\hline \multirow[t]{5}{*}{ AFTER } & Mkt-Rf & 0.704 & 28.968 & 0.973 & 17.685 & 0.626 & 16.509 & 0.799 & 16.270 \\
\hline & SMB & 0.328 & 5.235 & 0.294 & 2.075 & 0.258 & 2.638 & 0.118 & 0.930 \\
\hline & HML & -0.001 & -0.029 & 0.112 & 0.960 & 0.065 & 0.812 & 0.242 & 2.327 \\
\hline & RMW & -0.237 & -2.276 & -0.574 & -2.431 & 0.060 & 0.366 & -0.441 & -2.090 \\
\hline & CMA & 0.503 & 3.761 & -0.171 & -0.566 & 0.181 & 0.866 & 0.745 & 2.757 \\
\hline
\end{tabular}

Table 1. Consumption industry's regression result of Fama-French five factor. (From May 2019 to December 2020)

\section{DISCUSSION}

Due to the outbreak of the COVID-19, many countries and cities have been locked down. COVID-19 has changed the way people consume, which was caused by extensive time spent at home. This study evaluates the validity of Fama-French 5-factor model with relevant data of consumption-related industry before and after the pandemic in the U.S. stock market. The analysis compares the coefficients and their validity.

\section{1. $M K T$}

The factor Mkt-Rf indicates risk premium. The coefficient of MKT-RF nearly remained unchanged, which means that the consumption-related industry is positive related to the market, and the correlation remained unchanged. The reason is that consumptionrelated industry is a periodic industry. There is no doubt that the consumption-related market has become more active among investors with the relief of the epidemic.
The consumption-related market has become larger in size and more stable in sales, showing consistency with the whole market.

\section{2. $S M B$}

SMB factor is significant in terms of explaining consumption-related stocks return both before and after the global pandemic, and the power becomes larger after the outbreak of COVID-19. The coefficient of SMB is greater than 0 either before COVID-19 or after, which means in consumption-related industry, small-cap stocks can receive higher returns. The statistic test results support that SMB factor is significant in return prediction. Influenced by the pandemic. The increasing relationship between SMB and asset return reflects a stronger intention of high returns in small-cap stocks. Higher value of the coefficient means higher returns. The coefficient value of SMB increases after the global pandemic, which may be driven by the strong growth potential in small market value companies. During hard 
time, the small-cap consumption-related stocks usually have more flexibility and innovation. They are more likely to research and develop new consumption goods to meet different demands. In addition, for this kind of small company, the productivity loss is very little because the main product or service require smaller processes compared with other big companies in this industry. At the same time, consumption-related goods can be regarded as some kinds of necessities, which will stimulate these stock's development. When they are undervalued, investors tend to buy them for excess return. Unquestionably, the cheaper the stocks, the more space for appreciation.

\section{3. $H M L$}

HML represents the difference in returns between companies with a high market value and companies with a low market value. By referring to the HML figures, before the pandemic (2019.05.01-2020.02.28), almost all HML figures stayed between -1 to 1 and was not significant. Though they showed both positive and negative relationships between portfolio and value premium, the HML was too small. As a result, the relationship between portfolio and value premium was not strong during the pandemic. However, after the pandemic, the absolute value of HML generally increases, with almost half of the figures have an absolute value greater than 1 . In other words, HML had become more significant during the pandemic time. This illustrates the consumption stock portfolio became more unstable. There are 2 causes. First of all, consumption of food, beer, soda, and smoke increases a lot before and after the pandemic due to changes in government policy during the global pandemic. Secondly, all those goods are from manufacturing companies. During the pandemic, the rule of manufacturing changes. More and more companies start to rely more on Machinery, which means the productivity of physical rapidly decreases. This will cause companies to produce less food, beer, soda, and smoke during the pandemic. However, after that, companies worked more normally to produce more goods and services.

\section{4. $R M W$}

The RMW factor was significant in explaining the variation in stock prices of the consumption-related industry after the COVID-19 pandemic. Still, the RMW factor was not material before the COVID-19 explosion. During the pandemic, the magnitude of the food and soda industry increased. This is primarily impacted by government policies that encouraged the population to remain in the dwelling to minimize the spread of Covid19. Consequently, populations have begun to hoard food and soda, causing frequent shortages of food and soda in the market and rising prices of products from various related companies, and leading investors to invest more aggressively in them. Taking B\&G Foods, Inc. as an example, after three consecutive years of stock price declines in 2017, 2018, and 2019, its stock price rebounded in 2020 and is still on a slow upward trend. In parallel, based on the April-June quarter data released on July 31,2020 , by B\&G Foods, Inc., its net income is 44,911 thousand USD in the second quarter of 2020, with an increase of $146.07 \%$ year-over-year. For beer and smoke, however, the pandemic hit their sales. The entire market is in recession, and the company's profitability is no longer the focus of investors. They have shifted to rely on other factors to track market changes to make their own investment decisions. Therefore, the RMW factor no longer influences investment decisions, and the change in the share price of beer and smoke is no more intimately related to it.

\section{5. $C M A$}

CMA represents the yield gap between conservative and aggressive investment style firms. According to the result, before the outbreak, CMA factors are all greater than 1.96, which means they are distinguishable from zero and are valid. This also demonstrates investors in the consumption industry do not have much demand for return. As the coefficients are positive, it can be seen that the return is mainly due to the company's conservative investment style. This may indicate people are not very optimistic about the consumption market and prefer to gain lower return in a more conservative approach. After the pandemic, although CMA remains positive, the magnitude of the food and soda industry increase, which indicate investments tend to be less conservative. This is mainly affected by the government's policy, which encourages people to stay at home to reduce the spread of Covid-19. Therefore, people begin to stock up on food, causing food shortages and rising prices, leading to a more aggressive investment. However, CMA of the beer and smoke industry increase due to the lockdown. According to Statista, in the year to March 2020, bar sales have collapsed by $60 \%$ because of the outbreak [18]. This shows the pandemic undoubtedly hit the sales of beer and cigarettes sales, causing companies tend to be more cautious when investing in these markets. In addition, the positive correlation between investment and return of the consumption industry can also reflect that conservative firms can perform relatively well. It also points out the severity of the epidemic in the consumption industry.

\section{CONCLUSION}

This article analyzes the role Fama-French 5-factor model played in depicting the return of U.S. stocks before and after the COVID-19 and compares CAPM Model with Fama-French 5-factor model U.S. data. Data is processed by multiple linear regression. This 
article also elaborates the roles of each factor. Before the epidemic, MKT and SMB are mostly significant, but after the epidemic, beside MKT, HML is also significant. The 5-factor model is more applicable to the U.S. consumption-related industry after COVID-19. Both models are effective to help investors make their decisions in the consumption-related industry before the epidemic completely disappears. However, it does not mean that Fama-French 5-factor model is superior in any case. The choice of model depends on specific conditions of markets and the results of the regression.

\section{REFERENCES}

[1] Cao, Q., Leggio, K. B., \& Schniederjans, M. J. (2005). A comparison between Fama and French's model and artificial neural networks in predicting the Chinese stock market. Computers \& Operations Research, 32(10), 2499-2512.

[2] Cao, Q., Leggio, K. B., \& Schniederjans, M. J. (2005). A comparison between Fama and French's model and artificial neural networks in predicting the Chinese stock market. Computers \& Operations Research, 32(10), 2499-2512.

[3] Vernon, J. A., Golec, J. H., \& Dimasi, J. A. (2009). Drug development costs when financial risk is measured using the Fama-French three-factor model. Health Economics, 19(8), 1002-1005.

[4] Gaunt, C. (2004). Size and book to market effects and the Fama French three factor asset pricing model: evidence from the Australian stockmarket. Accounting and Finance, 44(1), 27-44.

[5] Cao, Q., Leggio, K. B., \& Schniederjans, M. J. (2005). A comparison between Fama and French's model and artificial neural networks in predicting the Chinese stock market. Computers \& Operations Research, 32(10), 2499-2512.

[6] Vernon, J. A., Golec, J. H., \& Dimasi, J. A. (2009). Drug development costs when financial risk is measured using the Fama-French three-factor model. Health Economics, 19(8), 1002-1005.

[7] Kubota, K., \& Takehara, H. (2018). Does the Fama and French Five-Factor Model Work Well in Japan? International Review of Finance, 18(1), 137-146.

[8] Chiah, M., Chai, D., Zhong, A., \& Li, S. (2016). A Better Model? An empirical investigation of the Fama-French five - factor model in Australia. International Review of Finance, 16(4), 595-638.

[9] Sun, Y. (2021). Analysis of Fore and Aft Covid-19 Impact on Industry Data Based on Fama-French Five Factors.
[10] Bannigidadmath, D., Narayan, P. K., Phan, D. H. B., \& Gong, Q. (2021). How stock markets reacted to COVID-19? Evidence from 25 countries. Finance Research Letters, 102161.

[11] Fernandes, N. (2020). Economic Effects of Coronavirus Outbreak (COVID-19) on the World Economy. Social Science Research Network.

[12] Chen, S., Igan, D., Pierri, N., \& Presbitero, A. (2020). Tracking the Economic Impact of COVID19 and Mitigation Policies in Europe and the United States. IMF Working Papers, 2020(125), 125.

[13] Fama, E. F., \& French, K. R. (2015, April). A fivefactor asset pricing model. ScienceDirect. https://www.sciencedirect.com/science/article/abs/ pii/S0304405X14002323

[14] McKibbin, W., \& Fernando, R. (2020). The global macroeconomic impacts of COVID-19: Seven scenarios. Research Papers in Economics.

[15] Petkova, R. (2006). Do the Fama-French factors proxy for innovations in predictive variables?. The Journal of Finance, 61(2), 581-612.

[16] Gharghori, P., Chan, H., \& Faff, R. (2007). Are the Fama-French factors proxying default risk? Australian Journal of Management, 32(2), 223-249.

[17] Gregory, A., Tharyan, R., \& Christidis, A. (2013). Constructing and testing alternative versions of the Fama-French and Carhart models in the UK. Journal of Business Finance \& Accounting, 40(12), 172-214.

[18] Statista. (2020, April 1). Decline in pub, bar and restaurant sales due to COVID-19 in the UK 2020. 